Research Paper

\title{
Factors Related to the Need for Surgery after the Diagnosis of Bicuspid Aortic Valve: One Center's Experience under a Conservative Approach
}

\author{
Josep M. Alegret ${ }^{\bowtie}$, Carme Ligero, Josep M. Vernis, Raúl Beltrán-Debón, Gerard Aragonés, Ignasi Duran, \\ Oscar Palazón, Andrés Hernández-Aparicio \\ Secció de Cardiologia. Hospital Universitari de Sant Joan. Institut d'Investigació Sanitària Pere Virgili. Universitat Rovira i Virgili, Reus, \\ Spain.
}

$\square$ Corresponding author: Josep M. Alegret, Hospital Universitari de Sant Joan, Institut d'Investigació Sanitària Pere Virgili. Universitat Rovira i Virgili, c/ Dr. Laporte, 43204 Reus, Spain. Tel: +34977310300; Fax: +34977319984; E-mail: txalegret@hotmail.com

(C) Ivyspring International Publisher. This is an open-access article distributed under the terms of the Creative Commons License (http://creativecommons.org/ licenses/by-nc-nd/3.0/). Reproduction is permitted for personal, noncommercial use, provided that the article is in whole, unmodified, and properly cited.

Received: 2012.10.17; Accepted: 2013.01.02; Published: 2013.01.09

\begin{abstract}
Background and Aim: Bicuspid aortic valve (BAV) increases the risk of aortic valve dysfunction and ascending aorta aneurysm and, consequently, the need for aortic valve replacement and/or aortic repair. However, there is no universal consensus about the surgical criteria and the predictors for surgery. The aim of this study was to investigate related factors to the need for surgery in the setting of a strict long-term follow-up with relatively conservative surgical criteria.

Methods: We prospectively followed I 20 patients after the diagnosis of BAV. Predisposing factors for a future need for aortic valve replacement and ascending aorta repair were assessed. Aortic surgery was indicated when the ascending aorta diameter was $\geq 55 \mathrm{~mm}$ and was recommended based on patient characteristics and in the presence of a severe aortic valve dysfunction with an aortic diameter $\geq 50 \mathrm{~mm}$.

Results: During follow-up (mean, 86 months), 34 patients (28\%) (mean age, 56 \pm 12 years) were surgically treated. Aortic valve dysfunction $(n=22 ; 64 \%)$ and ascending aorta dilatation $(n=12 ; 36 \%)$ were the indications for surgery. Aortic regurgitation was the most frequent valve dysfunction at the time of diagnosis for BAV, but aortic stenosis was the most frequent indication for surgery. The presence at surgery of either aortic regurgitation or stenosis was clearly related to age, with regurgitation predominating in patients under 55 years, and aortic stenosis in older patients.

Multivariate Cox analysis showed that aortic stenosis (hazard ratio 4.I, $\mathrm{p}=0.00 \mathrm{I}$ ), indexed ascending aorta dilatation (hazard ratio 3.0, $\mathrm{p}=0.03$ ) and left ventricular end-diastolic diameter $\geq 60 \mathrm{~mm}$ (hazard ratio $=4.0, p=0.0 \mathrm{l}$ ) at diagnosis were factors associated with future surgery. Aortic dissection was not observed in patients that did not undergo surgery.

Conclusions: A relatively conservative approach for the indication of ascending aortic surgery in BAV is safe. In this setting, the presence of aortic or left ventricle dilatation and aortic stenosis at diagnosis of BAV were predictive of the need for surgery in the follow-up.
\end{abstract}

Key words: aortic dilatation, aortic stenosis, aortic valve dysfunction, bicuspid aortic valve, surgery.

\section{Introduction}

Bicuspid aortic valve (BAV) is the most common congenital heart defect. BAV is commonly associated with the development of clinically relevant complications such as aortic valve dysfunction, infectious en- 
docarditis, heart failure, aortic dilatation and acute aortic syndrome (1-5). Additionally, surgical procedures such as aortic valve replacement and ascending aorta repair in the presence of ascending aorta dilatation may be required throughout the life of these patients, although possible predictive factors for future surgery have not been thoroughly assessed. The purpose of ascending aorta repair is the prevention of acute aortic syndromes and, in this sense, different guidelines have established different surgical criteria in the presence of ascending aorta dilatation and BAV $(6,7)$. Therefore, a universal consensus does not exist. Although some retrospective studies describe the clinical outcomes of patients with BAV (8-10), the prospective validation of a protocol of follow-up with established surgical criteria have not been thoroughly assessed.

Therefore, in the setting of a prospective protocol of follow-up under strict surgical criteria, we investigated possible predictive factors for future surgery after diagnosis of BAV that may be helpful in the prognosis assessment of BAV patients, with special attention paid to age, aortic valve dysfunction and aortic dimensions.

\section{Patients and methods}

Since late 1998, we have collected data and prospectively followed-up all patients with BAV diagnosed in our facilities. Therefore, patients older than 14 years diagnosed with BAV in our center were included in this study. All of these patients were identified from our reference population. Data presented were obtained at diagnosis of BAV. Clinical and echocardiographic follow-up was performed every year for patients without significant aortic valve dysfunction or aortic dilatation, but when significant lesions were present, the examination was performed every 6 months. We considered the presence of aortic stenosis when the mean gradient $\geq 20 \mathrm{mmHg}$. The grade of aortic regurgitation (grade 1 to 4 ) was assessed according to the usual criteria (7). We registered the aortic root diameter (measured at the level of sinus of Valsalva) and ascending aorta diameter (measured at the level of maximum diameter); both measures were made in end-diastole and indexed in relation to body surface area. A diagnosis of dilated aortic root/ascending aorta was made if the diameter indexed for body surface area was $>21 \mathrm{~mm} / \mathrm{m}^{2}$ (13). A diagnosis of BAV was made when two aortic leaflets were clearly visualized, with or without raphe, in the parasternal short-axis view through a transthoracic echocardiogram (11). When this procedure was deemed insufficient for the definitive diagnosis of $\mathrm{BAV}$, transesophageal echocardiogram (11) or cardiac magnetic resonance imaging (12) was performed.
Cardiovascular MRI also was performed at cardiologist criteria in the presence of a dilated ascending aorta/aortic regurgitation or in the setting of certain clinical studies.

All relevant clinical events (hospitalization, heart failure, cardiac surgery, death) were documented. We considered patients with severe aortic valve dysfunction and symptoms or those with a left ventricular ejection fraction $<50 \%$ as candidates for aortic valve replacement. In patients with aortic regurgitation, left ventricular end-diastolic diameter $>70 \mathrm{~mm}$ or left ventricular end-systolic diameter $>50$ were also considered. Ascending aortic repair was indicated when the diameter of the ascending aorta was $\geq 55 \mathrm{~mm}$ and was recommended based on patient characteristics and in the presence of severe aortic valve dysfunction with an ascending aortic diameter $\geq 50 \mathrm{~mm}$.

We included in this study 124 consecutive patients with a diagnosis of BAV identified prior to the end of 2009. Follow-up was considered complete if a clinical examination had been performed during the six month period prior to the analysis. Three patients were lost due to change of residence, and one patient was lost due to unknown reasons.

Written informed consent was obtained from all study participants in order to use their deposited data under anonymity. The study was approved by the local Ethics Committee of the Hospital Universitari de Sant Joan.

Cox survival analysis was performed to identify factors associated with the need for surgery during follow-up. We excluded from this analysis those patients who fulfilled criteria for the indication of surgery at diagnosis of BAV. Potential predictors of surgery were evaluated by univariate Cox regression analyses; data were censored at the time of surgery. Candidate variables with a $\mathrm{p}$ value $<0.10$ on univariate analysis were entered into a multivariate Cox regression model. The linearity and proportionality of the variables introduced in the model were assessed as required. Possible interactions between the variables of the model were analyzed. Differences were considered statistically significant if $\mathrm{p}<0.05$.

\section{Results}

The baseline clinical characteristics of the 120 patients with complete follow-up are shown in Table 1. Most patients were asymptomatic, male, with a high prevalence of valve dysfunction and aortic dilatation. Indexed dilated aortic root or ascending aorta was observed in $58 \%$ of patients, and $48 \%$ had an ascending aorta diameter $\geq 40 \mathrm{~mm}$. The mean follow-up time was $86 \pm 46$ months, and $53 \%$ of the patients were followed for more than six years. During this time, 8 $(7 \%)$ patients required hospitalization due to the de- 
velopment of heart failure, and 34 (28\%) were referred to a surgeon for aortic valve and/or aorta replacement. These patients' characteristics are presented in Table 2. Of note, six patients had a severe aortic valve dysfunction associated with symptoms or with an ejection fraction $<50 \%$ at the time of diagnosis. Aortic valve replacement was indicated in 3 of these cases, and replacement was dismissed in the other 3 due to comorbidity (Alzheimer disease, septic shock and stroke, respectively).

The mean age at surgery was $56 \pm 12$ years (range 31-75 years, median 55 years) (Table 2 ), and the mean period of time between the diagnosis of BAV and surgery was 46 months (range 1-135 months; median 37 months). Although aortic regurgitation was more prevalent at the time of diagnosis of BAV, aortic stenosis was the predominant valve dysfunction when surgery was indicated for aortic valve dysfunction. Aortic dilatation was an indication for surgery in 12 patients, but most $(n=10)$ presented a concomitant severe aortic valve dysfunction (regurgitation $(n=5)$, stenosis $(n=4)$ or double lesion $(n=1)$ ) that required aortic valve replacement. According to age, aortic regurgitation was the predominant valve dysfunction in patients younger than 55 years who underwent surgery (aortic regurgitation $64 \%$, aortic stenosis $36 \%$, double lesion $0 \%$ ), whereas in the older patients, the main valve dysfunction was aortic stenosis (aortic stenosis $67 \%$, aortic regurgitation $17 \%$, double aortic lesion $17 \%)(p=0.008)$.

Table I. Baseline clinical and echocardiographic characteristics at diagnosis of bicuspid aortic valve of the overall study population and segregated depending on the need for surgery.

\begin{tabular}{|c|c|c|c|c|}
\hline Characteristics & $\begin{array}{l}\text { Total } \\
(n=120)\end{array}$ & $\begin{array}{l}\text { Without } \\
\text { Surgery* } \\
(n=83)\end{array}$ & $\begin{array}{l}\text { Surgery } \\
(\mathrm{n}=34)\end{array}$ & $P$ \\
\hline Age, years (mean \pm SD) & $47 \pm 17$ & $45 \pm 19$ & $53 \pm 12$ & 0.006 \\
\hline Body surface area $\left(\mathrm{m}^{2}\right)$ & $1.84 \pm 0.20$ & $1.82 \pm 0.71$ & $1.87 \pm 0.27$ & 0.28 \\
\hline Male gender (\%) & $96(80)$ & $65(78)$ & $28(82)$ & 0.49 \\
\hline Hypertension & $37(31)$ & $23(28)$ & $13(38)$ & 0.44 \\
\hline Smoker & $28(23)$ & $18(21)$ & $10(29)$ & 0.48 \\
\hline Diabetes mellitus & $10(6)$ & $6(7)$ & $4(12)$ & 0.62 \\
\hline Coronary artery disease & $6(5)$ & $4(5)$ & $2(6)$ & 1 \\
\hline Stroke & $2(2)$ & $1(1)$ & $1(3)$ & 0.55 \\
\hline Aortic stenosis $^{\circ}$ & $37(31)$ & $14(17)$ & $22(65)$ & 0.0001 \\
\hline Aortic regurgitation & & & & 0.08 \\
\hline I & $40(33)$ & $28(34)$ & $12(35)$ & \\
\hline II & $31(26)$ & $25(30)$ & $5(15)$ & \\
\hline III & $28(23)$ & $15(18)$ & $12(35)$ & \\
\hline IV & $2(2)$ & 0 & $1(3)$ & \\
\hline Functional class NYHA & & & & 0.002 \\
\hline I & $114(95)$ & $83(100)$ & $30(88)$ & \\
\hline II & $2(2)$ & 0 & $1(3)$ & \\
\hline III-IV & $4(3)$ & 0 & $2(6)$ & \\
\hline LVEDD (mm) & $52 \pm 6$ & $51 \pm 6$ & $54 \pm 7$ & 0.04 \\
\hline LVEDD $\geq 60 \mathrm{~mm}$ & $12(10)$ & $4(5)$ & $8(22)$ & 0.008 \\
\hline $\operatorname{LVESD}(\mathrm{mm})$ & $33 \pm 6$ & $32 \pm 5$ & $34 \pm 8$ & 0.21 \\
\hline $\mathrm{LVESD} \geq 45 \mathrm{~mm}$ - & $4(4)$ & 0 & $4(12)$ & 0.005 \\
\hline LVEF (\%) & $69 \pm 10$ & $70 \pm 9$ & $67 \pm 12$ & 0.14 \\
\hline Aortic root (mm) & $37 \pm 7$ & $36 \pm 7$ & $40 \pm 7$ & 0.003 \\
\hline Ascending aorta (mm) & $40 \pm 8$ & $37 \pm 7$ & $46 \pm 7$ & 0.0001 \\
\hline Aortic root $\left(\mathrm{mm} / \mathrm{m}^{2}\right)$ & $20.2 \pm 3.6$ & $19.5 \pm 3$ & $21.9 \pm 4$ & 0.004 \\
\hline Ascending aorta $\left(\mathrm{mm} / \mathrm{m}^{2}\right)$ & $21.7 \pm 4.9$ & $20.5 \pm 0.4$ & $24.7 \pm 5$ & 0.0001 \\
\hline Indexed aortic dilatation & $70(58)$ & $38(46)$ & $32(87)$ & 0.0001 \\
\hline
\end{tabular}

LVEDD: Left ventricular end-diastolic diameter; LVESD: Left ventricular end-systolic diameter; LVEF: Left ventricle ejection fraction. Values represent N (\%) or mean \pm SD.

${ }^{\circ}$ Defined as a mean gradient $\geq 20 \mathrm{mmHg}$; Eleven patients without measures.

*Excluding 3 patients not treated surgically due to comorbidities. 
Table 2. Characteristics of patients referred for surgery at the moment of intervention and characteristics of surgical procedure $(n=34)$.

\begin{tabular}{ll}
\hline Characteristics & N (\%) or mean \pm SD \\
\hline Age at surgery, years & $56 \pm 12$ \\
Male gender & $28(82)$ \\
Hypertension & $13(38)$ \\
Diabetes mellitus & $4(12)$ \\
Coronary artery disease & $2(6)$ \\
Stroke & $1(3)$ \\
Predominant aortic valve dysfunction & \\
Aortic stenosis & $14(64)$ \\
Aortic regurgitation & $6(27)$ \\
Double aortic lesion & $2(9)$ \\
Ejection fraction (\%) & $65 \pm 12$ \\
Aortic root (mm) & $40 \pm 7$ \\
Ascending aorta (mm) & $46 \pm 8$ \\
Indexed aortic root (mm/m $\left.{ }^{2}\right)$ & $21.5 \pm 4.4$ \\
Indexed ascending aorta (mm/m $\left.{ }^{2}\right)$ & $25.1 \pm 5.3$ \\
Indexed aortic dilatation & $25(83)$ \\
Indication of surgery & \\
Symptoms & $15(46)$ \\
Aortic dilatation & $12(36)$ \\
Left ventricular dysfunction/diameters & $7(18)$ \\
Intervention & \\
Ascending aortic graft + aortic valve re- & $20(59)$ \\
placement & \\
Aortic valve replacement & $11(32)$ \\
Ascending aortic graft & $3(9)$ \\
\hline
\end{tabular}

At diagnosis of BAV, patients that required surgery during follow-up were older, had more symptoms, a higher prevalence of aortic stenosis and larger left ventricular and ascending aorta diameters (Table 1). We analyzed the factors related to the need for surgery during follow-up by means of Cox analysis. The presence of aortic stenosis or ascending aorta dilatation at diagnosis of BAV, as well as a left ventricular end-diastolic diameter $\geq 60 \mathrm{~mm}$, predicted the need for surgery (aortic stenosis Hazard Ratio $=4.1$, $\mathrm{p}=0.001$; ascending aorta dilatation Hazard Ratio $=3.0$, $\mathrm{p}=0.03$; left ventricular end-diastolic diameter $\geq 60 \mathrm{~mm}$ Hazard Ratio $=4.0, \mathrm{p}=0.01$; Table 3). The prognosis in the absence of these variables was excellent; the absence of these 3 factors predicted the absence of need for surgery during follow-up. On the other hand, when $\geq 2$ factors were present, the need for surgery ranged between 63\%-100\%. Aortic regurgitation (greater than or equal to moderate) in the absence of ascending aorta dilatation was not an independent predictive factor for surgery.

Cardiovascular mortality during follow-up was limited to the 3 patients in whom aortic valve replacement was dismissed due to comorbidity. Aortic dissection was not observed in this population.

Table 3. Clinical and echocardiographic factors at diagnosis related to the need for surgery during follow-up: univariate and multivariate analyses.

\begin{tabular}{|c|c|c|c|c|}
\hline Factors & $\begin{array}{l}\text { Univariate Analysis } \\
\text { HR }\end{array}$ & $\begin{array}{l}P \\
\text { value }\end{array}$ & $\begin{array}{l}\text { Multivariate } \\
\text { Analysis } \\
\text { HR }(95 \% \text { CI) }\end{array}$ & $\begin{array}{l}P \\
\text { value }\end{array}$ \\
\hline Age at diagnosis; each year & 1.01 & 0.06 & & \\
\hline Age at diagnosis $>45$ years & 2.20 & 0.05 & & 0.76 \\
\hline Male gender & 1.10 & 0.84 & & \\
\hline Body surface area $\left(\mathrm{m}^{2}\right)$ & 3.02 & 0.26 & & \\
\hline Smoking & 1.13 & 0.76 & & \\
\hline Hypertension & 1.44 & 0.36 & & \\
\hline Diabetes mellitus & 0.91 & 0.72 & & \\
\hline Aortic stenosis (mean gradient $\geq 20 \mathrm{mmHg}$ ) & 4.21 & 0.0001 & $4.1(1.9-9.3)$ & 0.0001 \\
\hline Aortic regurgitation $(\geq \mathrm{II} / \mathrm{IV})$ & 1.29 & 0.46 & & \\
\hline Left ventricular end-diastolic diameter (mm) & 1.06 & 0.11 & & \\
\hline Left ventricular end-diastolic diameter $\geq 60 \mathrm{~mm}$ & 3.4 & 0.02 & $4.0(1.4-11.9)$ & 0.01 \\
\hline Left ventricular end-systolic diameter (mm) & 1.03 & 0.50 & & \\
\hline Left ventricular ejection fraction (\%) & 0.99 & 0.55 & & \\
\hline Left ventricular ejection fraction $<60 \%$ & 1.2 & 0.72 & & \\
\hline Ascending aorta dilatation & 4.20 & 0.001 & $3.0(1.1-8.1)$ & 0.03 \\
\hline
\end{tabular}




\section{Discussion}

Most BAV patients develop aortic valve dysfunction and ascending aorta dilatation during their lives $(14,15)$. Therefore, current management includes repeated clinical and echocardiographic assessment to evaluate the functional state of the valve and measure the dimensions of the aorta $(6,7)$. Although it is well documented that aortic valve dysfunction may led to surgical treatment $(6,7,16)$, there is currently scarce data available to predict the need for future surgery, specifically in BAV patients. Of note, BAV is associated with anatomic and functional changes in the aortic root. Our data reveal some clinical implications for this issue. In particular, the presence of either aortic dilatation or moderate to severe aortic stenosis at diagnosis was frequently associated with a higher probability of future surgery. Age at diagnosis was also a relevant factor; interestingly, age also seems to be a major determinant of the type of valve dysfunction that modulates surgical referral. Taking into account all BAV patients, aortic regurgitation (moderate to severe) was the most frequent finding, but considering only those who underwent surgery, the frequency of aortic stenosis was higher among those $>55$ years. There are no simple explanations for such a difference, but our findings suggest that the presence of BAV and the associated tensile stress in its leaflets accelerates valve degeneration, representing an additive factor to age, as previously suggested. The geometry of the bicuspid valve entails abnormal leaflet stress, which is responsible for tissue remodeling at the raphe region and early leaflet degeneration and dysfunction $(17,18)$. In contrast, aortic regurgitation (greater than or equal to moderate), although very frequent in BAV patients, was rarely an indication for surgery in the absence of superimposed ailments, and, consequently, it was not a predictive factor of future surgery. Among patients surgically referred with the indication of aortic regurgitation, the concomitant presence of aortic dilatation (factor identified as predictor of surgery) was extremely frequent. Moreover, the diameter of the aortic root and ascending aorta is a predisposing factor in the occurrence and progression of aortic regurgitation due to the superimposed effect of an increased valve stress and defect in coaptation (19-21). Of note, our BAV patients had an excellent prognosis in the absence of either aortic dilatation or aortic stenosis. Obviously, the presence of a severe aortic regurgitation may condition the need for surgery in the long-term follow-up as reflected by the fact that left ventricular end-diastolic diameter, variable related to severe aortic regurgitation, was a predictor of surgery.

Ascending aorta dilatation was a common find- ing in our patients. In fact, we found a higher rate of aortic dilatation ( $\geq 40 \mathrm{~mm} 48 \%$ ) at diagnosis of BAV with respect to previous studies (> $40 \mathrm{~mm} 10 \%$ (9) to $15 \%(8))$, arising as a common indication for surgery. The causes and mechanisms that give rise to aortic dilatation are not clearly understood, and it appears that genetic and hemodynamic factors coexist. On the basis that BAV and aortic dilatation could be manifestations of a single gene defect, some data would support a genetic component, as BAV has some patterns of inheritance (22) and links to other genetic diseases, such as Turner syndrome (23). Some pathways have been proposed, as mutations have been found in genes related to signaling and the transcriptional regulators (NOTCH1) $(24,25)$, although the knowledge about the genetic link between BAV and aortic dilatation is currently scant. Aortic valve dysfunction and the characteristics of flow in the ascending aorta also appear to play a role $(1,14,15)$. Probably the most important clinical factor related to ascending aorta dilatation is the age of the patient. Thus, in a previous study described (8), the prevalence of aortic dilatation increased from $15 \%$ to $45 \%$ after a mean of follow-up of 15 years. We may suspect that the older age of our patient population was the main reason for these differences; the older age of our population is probably related to the accurate analysis of aortic valve morphology by means of image technics, including transesophageal echocardiography and cardioRM when required, which facilitated the morphology diagnosis of most aortic valves, including those of older patients with a stenotic/degenerative component added. Another factor to be considered is the detailed analysis of the aortic root and ascending aorta diameters performed in our BAV patients. In previous studies $(8,9)$, approximately $33-62 \%$ patients had no ascending aorta diameter measurements taken during follow-up. In our study, all patients had aortic root diameter measurements taken, and $98 \%$ had ascending aorta diameter measurements taken, which is a fact that may facilitate the detection of aortic dilatation. The older age of our patient population also may explain the similar rate of need for surgery in spite of a shorter follow-up.

As we have seen, the great majority of patients with BAV are asymptomatic at diagnosis. Thus, it is relevant to establish an accurate strategy of follow-up and to define adequate criteria for surgery for preventing aortic dissection or rupture. In recent years, different criteria for ascending aorta repair in the setting of BAV have been proposed from different scientific societies. Thus, the 2010 ACCF/AHA/AATS/ ACR/ASA/SCA/SCAI/SIR/STS/SVM guidelines (6) considered the risk of aortic dissection in BAV similar to other genetically-mediated aortic disorders, and 
proposed a more aggressive approach with respect to previous recommendations (16), including ascending aorta repair when the ascending aorta diameter was $\geq 45 \mathrm{~mm}$. Two studies on the natural history of BAV have described a low incidence of acute aortic complications, ranging from $0.03 \%$ (10) to $0.1 \%$ (9) per patient-year of follow-up. In an exhaustive study published after these guidelines by Michelena et al. (10), only 2 patients suffered aortic dissection under a native BAV (previous to surgery) and they both had an ascending aorta diameter $>50 \mathrm{~mm}$ (in one case 52 $\mathrm{mm}$ with a concomitant aortic stenosis, in the other case the ascending aorta diameter was $70 \mathrm{~mm}$ ). Recently modified guidelines from the European Society of Cardiology (7) propose a more conservative approach, establishing the threshold when the ascending aorta diameter is $\geq 50 \mathrm{~mm}$ and coexists with other risk factors or severe aortic valve dysfunction, and $\geq 55$ $\mathrm{mm}$ for the remaining patients. Our clinical follow-up is based in a strict clinical protocol without significant modifications since 1999; the criteria for aortic valve replacement used here are based on the classical indications recommended in the guidelines and our criteria for aortic repair are very similar to the conditions recommended for the new ESC recommendations. During follow-up, acute aortic syndromes were not present in non-surgically treated patients. Thus, we validated the safety of a relatively conservative approach in the recommendation of ascending aorta repair in BAV patients.

Our study has some limitations. A higher number of patients could allow other variables to increase in significance as predictors; for example the presence of aortic regurgitation without aortic dilatation. A multicenter study could validate these results. The recently published European Society of Cardiology (7) guidelines about valvular heart disease include other variables that should be considered as additional criteria for the indication of ascending aorta repair, such as a family history of dissection/rupture/sudden death, or an increase in aortic diameter $>2 \mathrm{~mm} /$ year. Because these criteria have been described recently, they were not considered as criteria for the indication of ascending aorta repair during the period of this follow-up and, thus, they were not included in the analysis. We analyzed the role of clinical variables and routine echocardiographic parameters as predictors of surgery. Other kinds of variables, such as biological markers related to aortic wall degeneration $(26,27)$ or parameters related to the biomechanical properties of the aortic wall (26), could play a role in the identification of patients at risk of aortic complications, and thus, potentially be indicators of surgery.

In summary, a relatively conservative approach for the indication of ascending aortic surgery in BAV is safe. In this setting, the presence of aortic or left ventricle dilatation and aortic stenosis at diagnosis of BAV were predictive of the need for surgery during follow-up. Age is related to the type of valve dysfunction observed at surgery.

\section{Acknowledgements}

The authors appreciate the support in the statistical analyses of Pilar Hernández.

\section{Competing Interests}

The authors have declared that no competing interest exists.

\section{References}

1. Hahn RT, Roman MJ, Mogtader AH, Devereux RB. Association of aortic dilation with regurgitant, stenotic and functionally normal bicuspid aortic valves. J Am Coll Cardiol 1992; 19: 283-288.

2. Tribouilloy C, Rusinaru D, Sorel C, Thuny F, Casalta JP, Riberi A, Jeu A, Gouriet F, Collart F, Caus T, Raoult D, Habib G. Clinical characteristics and outcome of infective endocarditis in adults with bicuspid aortic valves: a multicentre observational study. Heart 2010; 96:1723-9.

3. Nistri S, Sorbo MD, Marin M, Palisi M, Scognamiglio R, Thiene G. Aortic dilatation in young men with normally functioning bicuspid aortic valves. Heart 1999; 82:19-22.

4. Roberts CS, Roberts WC. Dissection of the aorta associated with congenital malformation of the aortic valve. J Am Coll Cardiol 1991; 17:712-6.

5. Oliver JM, Alonso-Gonzalez R, Gonzalez AE, Gallego P, Sanchez-Recalde A, Cuesta E, Aroca A, Lopez-Sendon JL. Risk of aortic root or ascending aorta complications in patients with bicuspid aortic valve with and without coarctation of the aorta. Am J Cardiol 2009; 104:1001-6.

6. Hiratzka LF, Bakris GL, Beckman JA, Bersin RM, Carr VF, Casey DE Jr, Eagle KA, Hermann LK, Isselbacher EM, Kazerooni EA, Kouchoukos NT, Lytle BW, Milewicz DM, Reich DL, Sen S, Shinn JA, Svensson LG, $\begin{array}{lll}\text { Williams } & 2010\end{array}$ ACCF/AHA/AATS/ACR/ASA/SCA/SCAI/SIR/STS/SVM Guidelines for the diagnosis and management of patients with thoracic aortic disease. J Am Coll Cardiol 2010; 55: e27-e129.

7. Vahanian A, Alfieri O, Andreotti F, Antunes MJ, Barón-Esquivias G, Baumgartner H, Borger MA, Carrel TP, De Bonis M, Evangelista A, Falk V, Iung B, Lancellotti P, Pierard L, Price S, Schäfers HJ, Schuler G, Stepinska J, Swedberg K, Takkenberg J, Von Oppell UO, Windecker S, Zamorano JL, Zembala M; ESC Committee for Practice Guidelines (CPG), Bax J, Baumgartner H, Ceconi C, Dean V, Deaton C, Fagard R, Funck-Brentano C, Hasdai D, Hoes A, Kirchhof P, Knuuti J, Kolh P, McDonagh T, Moulin C, Popescu BA, Reiner Z, Sechtem U, Sirnes PA, Tendera M, Torbicki A, Vahanian A, Windecker S. Guidelines on the management of valvular heart disease (version 2012): The Joint Task Force on the Management of Valvular Heart Disease of the European Society of Cardiology (ESC) and the European Association for Cardio-Thoracic Surgery (EACTS). Eur Heart J 2012; 33:2451-96.

8. Michelena HI, Desjardins VA, Avierinos JF, Russo A, Nkomo VT, Sundt TM, Pellikka PA, Tajik AJ, Enriquez-Sarano M. Natural history of asymptomatic patients with normally functioning or minimally dysfunctional bicuspid aortic valve in the community. Circulation 2008; 117:2776-84.

9. Tzemos N, Therrien J, Yip J, Thanassoulis G, Tremblay S, Jamorski MT, Webb GD, Siu SC. Outcomes in adults with bicuspid aortic valves. JAMA 2008; 300:1317-25.

10. Michelena HI, Khanna AD, Mahoney D, Margaryan E, Topilsky Y, Suri RM, Eidem B,Edwards WD, Sundt TM 3rd, Enriquez-Sarano M. Incidence of aortic complications in patients with bicuspid aortic valves. JAMA 2011; 306:1104-12.

11. Alegret JM, Palazón O, Duran I, Vernis JM. Aortic valve morphology definition with transthoracic combined with transesophageal echocardiography in a population with high prevalence of bicuspid aortic valve. Int J Cardiovasc Imag 2005; 21:213-7.

12. Gleeson TG, Mwangi I, Horgan SJ, Cradock A, Fitzpatrick P, Murray JG. Steady-state free-precession (SSFP) cine MRI in distinguishing normal and bicuspid aortic valves. J Magn Reson Imaging 2008; 28:873-8. 
13. Roman MJ, Devereux RB, Kramer-Fox R, O'Loughlin J. Two-dimensional echocardiographic aortic root dimensions in normal children and adults. Am J Cardiol 1989; 64: 507-12.

14. Alegret JM, Palomares R, Duran I, Palazón O, Vernis JM. Effect of age on valvular dysfunction and aortic dilatation in patients with a bicuspid aortic valve. Rev Esp Cardiol 2006; 59:503-6.

15. Della Corte A, Bancone C, Quarto C, Dialetto G, Covino FE, Scardone M, Caianiello G, Cotrufo M. Predictors of ascending aortic dilatation with bicuspid aortic valve: a wide spectrum of disease expression. Eur J Cardiothorac Surg 2007; 31:397-404.

16. Bonow RO, Carabello BA, Chatterjee K, de Leon AC Jr, Faxon DP, Freed MD, Gaasch WH, Lytle BW, Nishimura RA, O'Gara PT, O'Rourke RA, Otto CM, Shah PM, Shanewise JS, Smith SC Jr, Jacobs AK, Adams CD, Anderson JL, Antman EM, Fuster V, Halperin JL, Hiratzka LF, Hunt SA, Lytle BW, Nishimura R, Page RL, Riegel B. ACC/AHA 2006 guidelines for the management of patients with valvular heart disease: a report of the American College of Cardiology/American Heart Association Task Force on Practice Guidelines (writing Committee to Revise the 1998 guidelines for the management of patients with valvular heart disease) developed in collaboration with the Society of Cardiovascular Anesthesiologists endorsed by the Society for Cardiovascular Angiography and Interventions and the Society of Thoracic Surgeons. J Am Coll Cardiol 2006;48:e1-148.

17. Otto CM. Calcification of bicuspid aortic valves. Heart 2002; 88: 321-322.

18. Conti CA, Della Corte A, Votta E, Del Viscovo L, Bancone C, De Santo LS, Redaelli A. Biomechanical implications of the congenital bicuspid aortic valve: a finite element study of aortic root function from in vivo data. J Thorac Cardiovasc Surg. 2010; 140:890-6.

19. Shapiro LM, Thwaites B, Westgate C, Donaldson R. Prevalence and clinical significance of aortic valve prolapse. Br Heart J. 1985; 54: 179-183.

20. Stewart WJ, King ME, Gillam LD, Guyer DE, Weyman AE. Prevalence of aortic valve prolapse with bicuspid aortic valve and its relation to aortic regurgitation: a cross-sectional echocardiographic study. Am J Cardiol 1984; 54: 1277-1282.

21. Alegret JM, Palazón O, Duran I, Vernis JM. Factors related to aortic regurgitation in the presence of a dilated aortic root. Am J Cardiol 2005; 95: 417-420.

22. Calloway TJ, Martin LJ, Zhang X, Tandon A, Benson DW, Hinton RB. Risk factors for aortic valve disease in bicuspid aortic valve: a family-based study. Am J Med Genet A. 2011;155A:1015-20.

23. Donadille B, Rousseau A, Zenaty D, Cabrol S, Courtillot C, Samara-Boustani D, Salenave S, Monnier-Cholley L, Meuleman C, Jondeau G, Iserin L, Duranteau L, Cabanes L, Bourcigaux N, Bonnet D, Bouchard P, Chanson P, Polak M, Touraine P, Lebouc Y, Carel JC, Léger J, Christin-Maitre S. Cardiovascular findings and management in Turner syndrome: insights from a French cohort. Eur J Endocrinol 2012;167:517-22.

24. Garg V, Muth AN, Ransom JF, et al. Mutations in NOTCH1 cause aortic valve disease. Nature 2005;437:270-4.

25. Mohamed SA, Aherrahrou Z, Liptau H, et al. Novel missense mutations (p.T596M and p.P1797H) in NOTCH1 in patients with bicuspid aortic valve. Biochem Biophys Res Commun 2006;345:1460-5.

26. Ranasinghe AM, Bonser RS. Biomarkers in acute aortic dissection and other aortic syndromes. J Am Coll Cardiol 2010; 56: 1535-1541.

27. Kurihara T, Shimizu-Hirota R, Shimoda M, Adachi T, Shimizu H, Weiss SJ, Itoh H, Hori S, Aikawa N, Okada Y. Neutrophil-Derived Matrix Metalloproteinase 9 Triggers Acute Aortic Dissection. Circulation 2012 [Epub ahead of print].

28. Donato Aquaro G, Ait-Ali L, Basso ML, Lombardi M, Pingitore A, Festa P. Elastic properties of aortic wall in patients with bicuspid aortic valve by magnetic resonance imaging. Am J Cardiol 2011; 108: 81-87. 